\title{
Prevalence of stroke and stroke related risk factors: a population based cross sectional survey in southwestern China
}

\author{
Xingyang $\mathrm{Yi}^{{ }^{*}{ }^{*}{ }^{+}}$, Hua Luo ${ }^{2}$, Ju Zhou ${ }^{1+}$, Ming Yu ${ }^{3}$, Xiaorong Chen ${ }^{3}$, Lili $\operatorname{Tan}^{4}$, Wei Wei ${ }^{2}$ and Jie $\mathrm{Li}^{1}$
}

\begin{abstract}
Background: Stroke and its risk factors epidemiological survey can help identify individuals at higher risk and therefore promote stroke prevention strategies. The aim of this study was to estimate the current prevalence of stroke and high risk stroke population, and evaluate stroke associated risk factors in southwestern China.

Methods: This was a multi-center, cross sectional survey in southwestern China from May 2015 to September 2015. The eight communities were selected at random, and 17,413 residents aged $\geq 40$ years volunteered to participate in this survey. Data were collected through face-to-face survey using a structured questionnaire. Five hundred twentyone participants with incomplete questionnaires on stroke history or risk factors records were excluded.

Results: A total of 16,892 people included in analysis. The overall prevalence of stroke was $3.1 \%$ (95\% Cl 2.6-3.9\%), $17.1 \%$ of participants were the high risk stroke population. After full adjustments, hypertension, diabetes, dyslipidemia, overweight, lack of exercise and family history of stroke were significantly associated with overall stroke and ischemic stroke. The largest contributor was hypertension (population-attributable risk 23.6\%), followed by dyslipidemia, physical inactivity, family history of stroke, diabetes, and overweight. However, only hypertension $(\mathrm{OR}=3.66,95 \% \mathrm{Cl} 1.82-8.23)$ was significantly associated with hemorrhagic stroke.

Conclusions: The prevalence of stroke and high risk stroke population was high among adults aged $\geq 40$ years in southwestern China. Hypertension, dyslipidemia and lack of exercise were stronger contributors for stroke, these findings suggest that individual-level and population-level interventions for these leading risk factors are necessary to prevent stroke.
\end{abstract}

Keywords: Stroke, Epidemiology, Risk factors, Health care

\section{Background}

Stroke is a leading cause of adult mortality and disability, and there are approximately 3 million new stroke cases every year in China $[1,2]$. In the past several decades, the incidence of stroke has decreased because of effective strategies for preventing cerebrovascular risk factor and good health services in developed countries. However, the converse has been revealed for developing countries. In recent years, the economic climate in China has changed considerably, the epidemiologic features of stroke in China have likely changed substantially

\footnotetext{
* Correspondence: 1842942576@qq.com

${ }^{+}$Xingyang Yi and Ju Zhou contributed equally to this work.

${ }^{1}$ Department of Neurology, The People's Hospital of Deyang City, No 173,

North Taishan Road, Deyang 618000, Sichuan, China

Full list of author information is available at the end of the article
}

in the last decades [3]. However, rare comprehensive community-based surveys have been completed since the 1990s to support these changes in China [4], except several hospital-based registration studies [5].

The China National Stroke Screening Survey (CNSSS) is one community-based stroke surveillance program in China [6]. The aims of the survey are to monitor stroke trends, identify high risk factors for stroke, investigate the current epidemiologic features of stroke, and assess intervention policies in China. The results of CNSSS in part showed that the adjusted stroke prevalence was $2.06 \%$ in adults aged $\geq 40$ years, the incidence of stroke in China increased rapidly in 2002 to 2013 in China [1]. Given that China had the highest number of prevalent cases of stroke in the world [7], and more recently 
reported by results of the Global Burden of Disease Study [8], more vigorous and effective interventions are needed to prevent stroke.

In China, the prevalence of stroke is different in different regions and between rural and urban areas [9]. The prevalence of stroke in rural areas sharply increased between 2003 and 2013, whereas in urban areas the prevalence was stable in the same period. A north-to-south geographical gradient in stroke prevalence, incidence and mortality is apparent, with numbers being lowest in the south and highest in the northeast of China [10]. A recent study also showed that stroke prevalence exhibited a noticeable north-south gradient (1097.1, 917.7, and 619.4 in the north, middle, and the south, respectively), and stroke prevalence was higher in the rural regions than in the urban (945.4 versus 797.5) regions in China [11]. However, with regarding to mortality-toincidence ratio (MIR) of stroke, the MIR is the highest in the southwest and the lowest along the eastern and southern coasts [10]. These regional differences in MIR indicate striking disparities in both access to and quality of stroke care across the country [12].

Accurate provincial and regional-level stroke prevalence estimates are very important for research planning and targeted strategies for stroke prevention and management. Sichuan is located in Southwestern of China, and is an economically underdeveloped area, with an area of $486,000 \mathrm{~km}^{2}$ and 73.02 million inhabitants. The prevalence and incidence of stroke in Sichuan province was very high in China according to CNSSS [13], and since then, rare studies have revisited this important public health issue. In recent years, the economic climate, people's dietary habits, awareness and health concepts in Sichuan have changed considerably. Considering these developments, the epidemiology of stroke in Sichuan may have changed. Thus, we hypothesized that the prevalence of stroke in Sichuan could increase over time, the features of different population groups could vary, and certain risk factors, including metabolic diseases and unhealthy lifestyle, would have major contributions to burden of stroke. Hence, we performed one community-based stroke survey in $8 \mathrm{com}$ munities in Sichuan province according to CNSSS program between September 2014 and September 2015. This study aims to estimate the stroke prevalence and the pattern of its related risk factors, and fill the information gap in this field in Sichuan.

\section{Methods}

\section{Study design and participants}

This population based cross sectional study was part of the CNSSS (grant No. 2011BAI08B01) and was carried out in the Sichuan province from May 2015 to September 2015. All methods of survey were performed in accordance with the CNSSS program and approved by the Stroke Screening and Prevention Programme of the National Health and Family Planning Commission of China. The survey protocol was reviewed and approved by the Ethics Committee of the participating hospitals (the People's Hospital of Deyang City, the Affiliated Hospital of Southwest Medical University, and Suining Central Hospital), and informed consent was obtained from all participants during recruitment.

A cluster survey method was used, and 8 communities in Sichuan were selected at random. The stroke surveillance methods were compiled by the National Center for Stroke Control and Prevention. More details on the organization and implementation can be found at the official website [13]. Briefly, the CNSSS is a cross-sectional survey with a 2-stage stratified sampling framework. We only screened all residents for ages $\geq 40$ years in each community, because the prevalence of stroke is very low among younger adults [14]. All participants were people who had lived in the county for at least 6 months, and were initially screened using a structured face-to-face questionnaire by interviewers. The questionnaire included demographic characteristics (eg, age, gender, education level and employment), stroke related behavioural factors (eg, drinking, smoking, exercise habits and diet), personal and family medical history of stroke and chronic diseases (ie, hypertension, diabetes mellitus, dyslipidemia and atrial fibrillation $[\mathrm{AF}]$ ), and physical examination (eg, height, weight, resting blood pressure). More detailed information regarding the lifestyle, related diseases, and laboratory examinations (such as fasting blood glucose [FBG], lipid, electrocardiogram [ECG], and carotid ultrasonography) was also obtained from the individuals who had experienced stroke and from the participants who were identified to be at a high risk for stroke.

\section{Definitions of stroke and evaluation of risk factors}

According to the World Health Organization criteria, stroke was defined as "rapidly developing clinical signs of focal (or global) disturbance of cerebral function, lasting more than $24 \mathrm{~h}$ or leading to death, with no apparent cause other than that of vascular origin [15]". In this survey, stroke history and stroke types were established by a combination of self-reporting and the judgment of a physician or neurologist according to neuroimaging (including brain computed tomography scan and magnetic resonance imaging). Subtypes of stroke included ischemic stroke and hemorrhagic stroke. By definition, patients with a history of transient ischemic attack only were excluded.

According to CNSSS program $[1,6]$, the eight conventional stroke risk factors were assessed in the CNSSS questionnaire included behavioral factors (overweight/ 
obesity, smoking, physical inactivity), family history of stroke, and biomedical factors (hypertension, diabetes, dyslipidemia, and AF). Eight stroke related risk factors were defined as follows: hypertension was defined as a self-reported history or the use of antihypertensive drugs, or the average of two resting systolic blood pressure readings of $\geq 140 \mathrm{mmHg}$ and/or diastolic blood pressure $\geq 90 \mathrm{mmHg}$ in the field survey [16]. Diabetes mellitus was defined as the use of insulin and/or oral hypoglycaemic medications, or a self-reported history of diabetes or FBG $\geq 7.0 \mathrm{mmol} / \mathrm{L}$ in the field survey [17]. Dyslipidemia was defined as using a lipid-lowering medication or having one or more of the following in the field survey: triglycerides (TG) $\geq 1.70 \mathrm{mmol} / \mathrm{L}$, cholesterol $(\mathrm{TC}) \geq 5.18 \mathrm{mmol} / \mathrm{L}$, and low-density lipoprotein cholesterol (LDL-C) $\geq 3.37 \mathrm{mmol} / \mathrm{L}[18]$. AF was defined as reported by the respondent or diagnosed by ECG in the field survey. Current smoking ( $\geq 1$ cigarette per day) was defined by subjects' self-report. Body mass index (BMI) was calculated as weight $(\mathrm{kg})$ divided by height squared $\left(\mathrm{m}^{2}\right)$, and overweight or obesity was defined as BMI $\geq 26 \mathrm{~kg} / \mathrm{m}^{2}$ [19]. Physical inactivity was defined as physical exercise $<3$ times a week for $<30$ min each time, and this included industrial and agricultural labour [20]. A family history of stroke was restricted to immediate family members.

Subjects with at least three of the aforementioned eight stroke related risk factors or a history of stroke were classified as the high risk population for stroke.
The risk assessment scales for stroke referred were designed by the CNSSS, and have been proved to have good reliability and validity compared with the modified scale of the Framingham Stroke Profile (FSP), and can be used as an evaluation tool for stroke risk assessment [21].

\section{Data cleaning procedures and quality control}

The detailed data cleaning procedure and quality control according to the CNSSS is presented in Fig. 1. Briefly, 18,595 participants volunteered to participate in the face-to-face survey, questionnaires were obtained in 17 , 413 participants. The response rate was $93.6 \%(17,413 /$ 18595). Five hundred twenty-one participants with incomplete questionnaires on stroke history or risk factors records were exclude. Finally, 16,892 valid individual records (including 524 stroke cases [429 ischemic stroke, 95 hemorrhagic stroke]) were enrolled. After the data cleaning procedure, there were no missing values in the variables assessed.

The interviewers were physicians or neurologists from community hospitals, who had at least 5 years of education in medicine. The quality of the measurements and data collection were maintained by implementing uniform training and standardized protocols. The staff involved in the survey were trained by the CNSSS program and passed the examination at the end of train. All data were entered electronically into a data terminal that was directly connected with the CNSSS database.

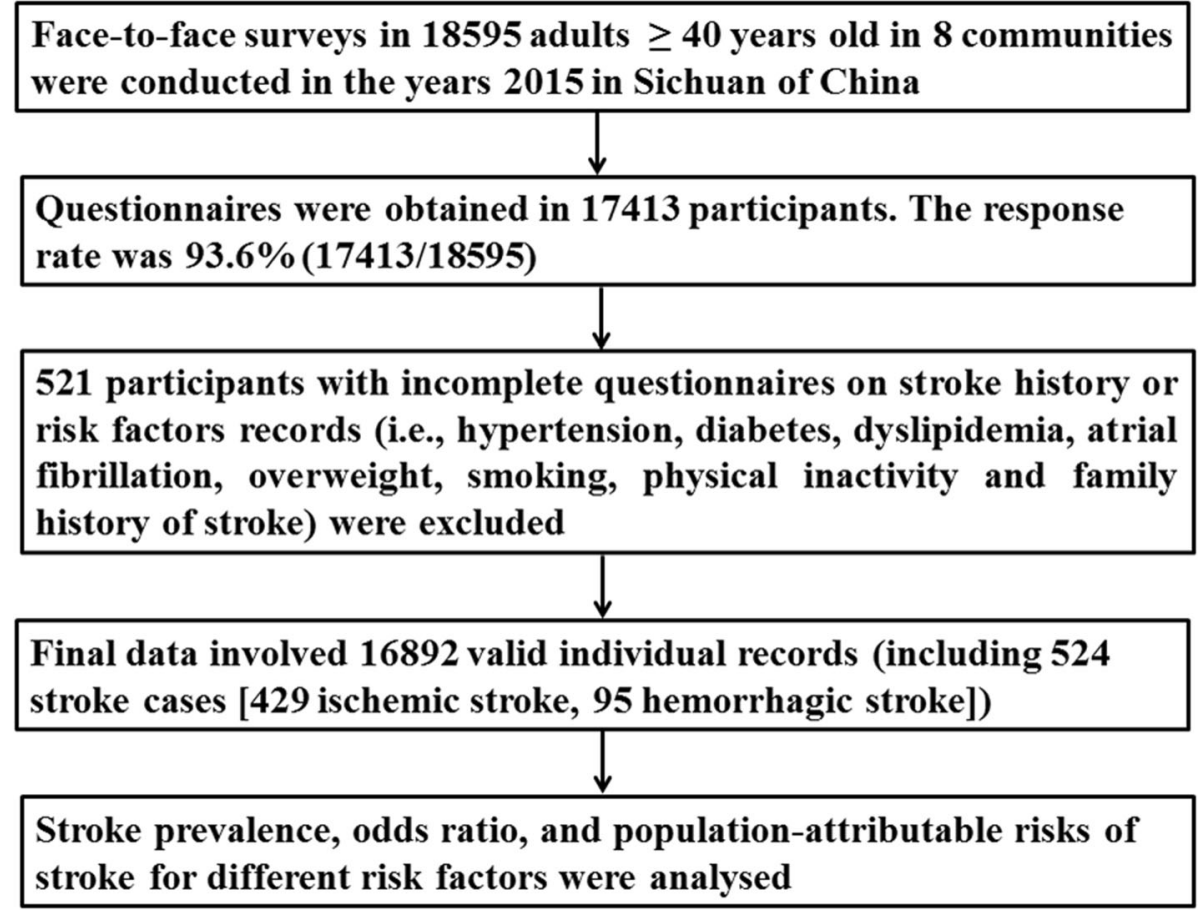

Fig. 1 Data preparing and cleaning process in this survey 


\section{Sample size estimates and statistical analysis}

According to the CNSSS, screening should cover at least $1 \%$ of the local residents aged $\geq 40$ years. There were 167 , 553 residents aged $\geq 40$ years in the 8 communities according to the sixth national population census in 2010 [22], $10 \%$ of the targeted population, therefore, the expected sample size was 16,755 . The sample size $(\mathrm{N})$ necessary for this cross sectional study was calculated based on a prevalence (p) of stroke of $2.37 \%$ among adults aged $\geq 40$ years in China [6], with a $0.5 \%$ uncertainty level $(\mathrm{d})$, using the formula $\mathrm{n}=\mathrm{t} \alpha^{2} \mathrm{pq} / \mathrm{d}^{2}(\mathrm{t}=1.96$, $\alpha=95 \%$ for both sides; $q=1-p$ ), we calculated a required sample size of 16,765 . Considering a lost to follow-up rate of $10 \%$, the planned sample size was 18 , $628(16,765 / 0.90)$. Finally, 18,595 participants aged $\geq 40$ years participated in this survey.

Descriptive analyses were conducted to determine the distribution of the demographic data and risk factors in the study population using SPSS 17.0 (SPSS Inc. New York, New York, USA). Categorical variables are presented as proportions and were compared using $\mathrm{X} 2$ tests between different subgroups. The adjusted odds ratios (ORs) and 95\% confidence intervals (CIs) of each risk factor for stroke prevalence rate were derived using unconditional multivariate logistic regression models, fully adjusting for all other potential confounders, including age, sex, education, urban/rural residency, smoking, physical inactivity, overweight, hypertension, diabetes, dyslipidemia, AF, and family history of stroke.

We calculated population-attributable risks (PARs) of stroke, ischemic stroke and hemorrhagic stroke from the model using the Bruzzi method for determining the confounder-adjusted PAR [23], which has been applied in many previous studies. The $95 \%$ CIs were evaluated for the PARs according to the previously described procedure [24].

All tests were two-sided, and $P$ value $<0.05$ was considered statistically significant.

\section{Results}

The baseline characteristics of the study population were shown in Table 1. In total of 16,892 participants, there were 524 stroke cases (3.1\%), 2893 participants (17.1\%) were the high risk stroke population. Of the 524 stroke cases, ischemic stroke accounted for 429 (81.9\%), hemorrhagic stroke accounted for 95 (18.1\%). The overall prevalence of stroke was $3.1 \%$ (95\% CI $2.6-3.9 \%)$.

The prevalence rate (unadjusted [crude]) of stroke was significantly higher in men than in women $(3.7 \%$ vs $2.8 \%, P=0.003$ ) and in individuals with a primary school level of education or below than in individuals with a college level of education or above $(4.4 \%$ vs $0.7 \%$, $P<0.001)$. The prevalence rate of stroke increased with age $(P<0.001)$. However, there was no statistically significant difference in stroke prevalence rate between rural populations and urban populations $(3.3 \%$ vs $2.9 \%$, $P=0.186$ ). Similar to the overall prevalence rate of stroke, the prevalence rate of ischemic stroke and hemorrhagic stroke was also significantly higher in men than in women $(2.9 \%$ vs $2.4 \%, P=0.029$, and $0.8 \%$ vs $0.5 \%, P=0.006$, respectively), and the prevalence rate of ischemic stroke and hemorrhagic stroke also increased with age (all $P<0.001$ for ischemic stroke and hemorrhagic stroke), but decreased with educational level $(P<0.001$ and $P=0.017$, respectively). In addition, the prevalence rate of ischemic stroke was higher in rural populations than in urban populations $(2.8 \%$ vs $2.3 \%, P=0.026)$, but there was no statistically significant difference in hemorrhagic stroke rate between rural and urban residents $(0.5 \%$ vs $0.6 \%, P=0.173)$ (Table 1$)$.

The crude prevalence rates of stroke were significantly different according to all risk factors, including hypertension, diabetes, dyslipidemia, AF, overweight, smoking, physical inactivity and family history of stroke. Stratified by risk factors, the crude stroke prevalence rate was the highest in the residents with AF (6.0\%), followed by those with hypertension (4.5\%), dyslipidemia (4.4\%), overweight (4.1\%), family history of stroke (3.9\%), diabetes and smoking (3.8\%), and physical inactivity (3.7\%) (Table 1).

Adjusted ORs for the individual risk factors by multivariable logistic regression model were showed in Table 2. The multivariable logistic regression showed that multiple characteristics were significantly associated with stroke, including age, gender, hypertension, diabetes, dyslipidemia, overweight, lack of exercise and family history of stroke. The strongest risk factors for overall stroke were hypertension (OR $=3.38,95 \%$ CI 1.65-5.23), dyslipidemia (OR $=2.15,95 \%$ CI $1.39-3.17)$ and physical inactivity $(\mathrm{OR}=1.95,95 \% \mathrm{CI} 1.37-3.37)$, followed by family history of stroke (OR $=1.87,95 \%$ CI $1.32-2.33)$, diabetes $(\mathrm{OR}=1.57,95 \%$ CI 1.33-2.14), and overweight ( $\mathrm{OR}=1.36,95 \% \mathrm{CI} 1.13-1.69)$. These patterns were consistent for ischemic stroke (Table 3). However, the multivariate analyses model found that only hypertension $(\mathrm{OR}=3.66,95 \% \mathrm{CI} 1.82-8.23)$ was significantly associated with hemorrhagic stroke (Table 4).

Hypertension (23.6\%), dyslipidemia (10.8\%), and physical inactivity $(10.3 \%)$ were the 3 risk factors with the largest contributions to the PAR of stroke after full adjustments (Table 2). Family history of stroke, overweight/obesity, diabetes, smoking, and atrial fibrillation each accounted for $<10 \%$ of the total PAR of stroke. Furthermore, the results of PAR for ischemic and hemorrhagic stroke were shown in Table 3 and Table 4.

\section{Discussion}

In this study, the results showed that high risk populations for stroke were very common in Sichuan of 
Table 1 Demographic characteristics of study populations and stratified prevalence of stroke [n(\%)]

\begin{tabular}{|c|c|c|c|c|}
\hline Variables & High risk population for stroke & Overall stroke & Ischemic stroke & Hemorrhagic stroke \\
\hline Total $(n=16,892)$ & $2893(17.1 \%)$ & $524(3.1 \%)$ & $429(2.5 \%)$ & $95(0.6 \%)$ \\
\hline \multicolumn{5}{|l|}{ Sex } \\
\hline $\operatorname{Male}(n=5411)$ & $1370(25.3 \%)$ & $201(3.7 \%)$ & $158(2.9 \%)$ & $43(0.8 \%)$ \\
\hline Female $(n=11,481)$ & $1523(13.3 \%)$ & $323(2.8 \%)$ & $271(2.4 \%)$ & $52(0.5 \%)$ \\
\hline$P$ value & $<0.001$ & $0.003(9.94)$ & $0.029(4.65)$ & $0.006(7.68)$ \\
\hline \multicolumn{5}{|l|}{ Age, y } \\
\hline $40-49(n=3524)$ & $318(9.0 \%)$ & $37(1.0 \%)$ & $30(0.8 \%)$ & $7(0.2 \%)$ \\
\hline $50-59(n=5106)$ & $686(13.4 \%)$ & $103(2.0 \%)$ & $87(1.7 \%)$ & $16(0.3 \%)$ \\
\hline $60-69(n=5803)$ & $1125(19.4 \%)$ & $228(3.9 \%)$ & $188(3.2 \%)$ & $40(0.7 \%)$ \\
\hline $70-79(n=2183)$ & $629(28.8 \%)$ & $131(6.0 \%)$ & $106(4.9 \%)$ & $25(1.1 \%)$ \\
\hline$\geq 80(n=276)$ & 135 (48.9\%) & $25(9.1 \%)$ & $18(6.5 \%)$ & $7(2.5 \%)$ \\
\hline$P$ value & $<0.001$ & $<0.001$ & $<0.001$ & $<0.001$ \\
\hline \multicolumn{5}{|l|}{ Residence } \\
\hline $\operatorname{Urban}(n=8889)$ & $1361(15.3 \%)$ & $260(2.9 \%)$ & $203(2.3 \%)$ & $57(0.6 \%)$ \\
\hline $\operatorname{Rural}(n=8003)$ & $1532(19.1 \%)$ & $264(3.3 \%)$ & $226(2.8 \%)$ & $38(0.5 \%)$ \\
\hline$P$ value & $<0.001$ & $0.186(1.96)$ & $0.026(4.96)$ & $0.173(2.09)$ \\
\hline \multicolumn{5}{|l|}{ Education } \\
\hline Primary school or below $(n=8331)$ & $1948(23.4 \%)$ & $369(4.4 \%)$ & $310(3.7 \%)$ & $59(0.7 \%)$ \\
\hline Junior middle school $(n=3312)$ & $568(17.1 \%)$ & $106(3.2 \%)$ & $83(2.5 \%)$ & $23(0.7 \%)$ \\
\hline Senior middle school $(n=3111)$ & $228(7.3 \%)$ & $33(1.1 \%)$ & $23(0.7 \%)$ & $10(0.3 \%)$ \\
\hline College or above $(n=2138)$ & $149(0.7 \%)$ & $16(0.7 \%)$ & $13(0.6 \%)$ & $3(0.1 \%)$ \\
\hline$P$ value & $<0.001$ & $<0.001$ & $<0.001$ & $0.017(10.6)$ \\
\hline \multicolumn{5}{|l|}{ Overweight/obesity } \\
\hline $\operatorname{Yes}(n=8615)$ & $1545(17.9 \%)$ & $355(4.1 \%)$ & $290(3.4 \%)$ & $65(0.8 \%)$ \\
\hline $\mathrm{No}(n=8277)$ & $1348(16.3 \%)$ & $169(2.0 \%)$ & $139(1.7 \%)$ & $30(0.4 \%)$ \\
\hline$P$ value & $0.004(8.07)$ & $<0.001$ & $<0.001$ & $<0.001$ \\
\hline \multicolumn{5}{|l|}{ Smoking } \\
\hline $\operatorname{Yes}(n=3676)$ & $748(20.3 \%)$ & $139(3.8 \%)$ & $114(3.1 \%)$ & $25(0.7 \%)$ \\
\hline $\mathrm{No}(n=13,216)$ & $2145(16.2 \%)$ & $385(2.9 \%)$ & $315(2.4 \%)$ & $70(0.5 \%)$ \\
\hline$P$ value & $<0.001$ & $0.006(7.2)$ & $0.017(5.98)$ & $0.283(1.16)$ \\
\hline \multicolumn{5}{|l|}{ Physical inactivity } \\
\hline $\operatorname{Yes}(n=8226)$ & $1752(21.3 \%)$ & 305 (3.7\%) & $251(3.1 \%)$ & $54(0.7 \%)$ \\
\hline $\mathrm{No}(n=8666)$ & 1141 (13.2\%) & $219(2.5 \%)$ & $178(2.1 \%)$ & $41(0.5 \%)$ \\
\hline$P$ value & $<0.001$ & $<0.001$ & $<0.001$ & $0.124(2.54)$ \\
\hline \multicolumn{5}{|l|}{ Hypertension } \\
\hline Yes $(n=7018)$ & 2082 (29.7\%) & $313(4.5 \%)$ & $246(3.5 \%)$ & $67(1.0 \%)$ \\
\hline $\mathrm{No}(n=9874)$ & $811(8.2 \%)$ & $211(2.1 \%)$ & $183(1.9 \%)$ & $28(0.3 \%)$ \\
\hline$P$ value & $<0.001$ & $<0.001$ & $<0.001$ & $<0.001$ \\
\hline \multicolumn{5}{|l|}{ Diabetes } \\
\hline $\operatorname{Yes}(n=2754)$ & 780 (28.3\%) & $106(3.8 \%)$ & 94 (3.4\%) & $12(0.4 \%)$ \\
\hline $\mathrm{No}(n=14,138)$ & $2113(14.9 \%)$ & $418(3.0 \%)$ & 335 (2.4\%) & $83(0.6 \%)$ \\
\hline$P$ value & $<0.001$ & $0.013(6.1)$ & $0.003(10.1)$ & $0.323(0.94)$ \\
\hline \multicolumn{5}{|l|}{ Dyslipidemia } \\
\hline $\operatorname{Yes}(n=3235)$ & 822 (25.4\%) & $141(4.4 \%)$ & $108(3.3 \%)$ & $33(1.0 \%)$ \\
\hline
\end{tabular}


Table 1 Demographic characteristics of study populations and stratified prevalence of stroke [n(\%)] (Continued)

\begin{tabular}{|c|c|c|c|c|}
\hline Variables & High risk population for stroke & Overall stroke & Ischemic stroke & Hemorrhagic stroke \\
\hline $\mathrm{No}(\mathrm{n}=13,657)$ & $2071(15.2 \%)$ & $383(2.8 \%)$ & $321(2.4 \%)$ & $62(0.5 \%)$ \\
\hline$P$ value & $<0.001$ & $<0.001$ & $<0.001$ & $<0.001$ \\
\hline \multicolumn{5}{|l|}{ Atrial fibrillation } \\
\hline $\operatorname{Yes}(n=232)$ & $72(31.0 \%)$ & $14(6.0 \%)$ & $13(5.6 \%)$ & $1(0.4 \%)$ \\
\hline $\mathrm{No}(\mathrm{n}=16,660)$ & $2821(17.1 \%)$ & $510(3.1 \%)$ & $416(2.5 \%)$ & $94(0.6 \%)$ \\
\hline$P$ value & $<0.001$ & $0.009(6.7)$ & $0.006(8.9)$ & $0.138(2.2)$ \\
\hline \multicolumn{5}{|l|}{ Family history } \\
\hline Yes $(n=2224)$ & $528(23.7 \%)$ & $86(3.9 \%)$ & $55(2.5 \%)$ & $31(1.4 \%)$ \\
\hline $\mathrm{No}(\mathrm{n}=14,668)$ & $2365(16.1 \%)$ & $438(2.9 \%)$ & $374(2.5 \%)$ & $64(0.4 \%)$ \\
\hline$P$ value & $<0.001$ & $0.027(4.98)$ & $0.984(0.05)$ & $<0.001$ \\
\hline
\end{tabular}

The prevalence rates stratified by demographic characteristics and risk factors are crude estimates

southwestern China. We have also identified a high prevalence of stroke and stoke related risk factors among adults aged $\geq 40$ years, and found that age, male, diabetes, hypertension, dyslipidemia, lack of exercise, overweight were associated with a high prevalence of stroke and ischemic stroke. These findings were consistent with those of previous studies on stroke prevalence in China $[1,20]$.

The prevalence of stroke in Sichuan was higher than the nationwide findings $[1,6]$, but was lower than in northeast China [20]. The prevalence of stroke increased with age, and this was consistent with other studies [25]. In the past decades, rapid economic development in China has increased life expectancies, the percentage of elderly people in population has also increased. The effect of population ageing on the stroke prevalence and disability-adjusted life years (DALYs) has become more and more serious in China. Our results also revealed that the prevalence of stroke was higher in men than in women, this was in accordance with other previous studies in China $[25,26]$. Stroke prevalence was higher in the rural regions than in the urban in China $[1,9,11]$. Income, the proportions and amount of awareness for stroke, and treatment and control of hypertension were lower in rural residents than urban residents, which may substantially affect the stroke prevalence [11]. In addition, smoking prevalence and salt intake is higher

Table 2 Odds ratios and population-attributable risk factors for overall stroke by multivariable regression models

\begin{tabular}{|c|c|c|c|c|c|}
\hline Variables & Reference groups & Control groups & Odds ratio $(95 \% \mathrm{Cl})$ & $P$ value & PAR (\%) $(95 \% \mathrm{Cl}$ \\
\hline Sex & Female & Male & $1.42(1.31-2.02)$ & 0.004 & NA \\
\hline \multirow[t]{4}{*}{ Age, y } & \multirow[t]{4}{*}{$40-49$} & $50-59$ & $1.86(1.42-2.86)$ & \multirow[t]{4}{*}{$<0.001$} & NA \\
\hline & & $60-69$ & $4.07(2.48-4.77)$ & & NA \\
\hline & & 70-79 & $5.36(2.66-6.89)$ & & NA \\
\hline & & $\geq 80$ & $6.21(2.94-7.35)$ & & NA \\
\hline Residence & Rural & Urban & $0.92(0.83-1.02)$ & 0.324 & NA \\
\hline \multirow[t]{3}{*}{ Education } & \multirow[t]{3}{*}{ Primary school or below } & Junior middle school & $1.02(0.86-2.03)$ & \multirow[t]{3}{*}{0.436} & NA \\
\hline & & Senior middle school & $0.98(0.87-1.53)$ & & NA \\
\hline & & College or above & $0.89(0.84-1.12)$ & & NA \\
\hline Overweight/obesity & No & Yes & $1.36(1.13-1.69)$ & 0.015 & $6.3(5.33-8.54)$ \\
\hline Smoking & No & Yes & $1.32(0.67-1.87)$ & 0.652 & $5.2(0.92-5.83)$ \\
\hline Physical inactivity & No & Yes & $1.95(1.37-3.37)$ & $<0.001$ & $10.3(8.3-12.6)$ \\
\hline Hypertension & No & Yes & $3.38(1.65-5.23)$ & $<0.001$ & $23.6(19.8-28.7)$ \\
\hline Diabetes & No & Yes & $1.57(1.33-2.14)$ & 0.023 & $6.9(5.92-7.33)$ \\
\hline Dyslipidemia & No & Yes & $2.15(1.39-3.17)$ & $<0.001$ & $10.8(8.8-10.23)$ \\
\hline Atrial fibrillation & No & Yes & $1.33(0.76-2.52)$ & 0.433 & $2.2(0.95-3.82)$ \\
\hline Family history & No & Yes & $1.87(1.32-2.33)$ & 0.008 & $8.2(9.13-16.8)$ \\
\hline
\end{tabular}

Cl confidence interval, PAR population-attributable risk, NA not applicable 
Table 3 Odds ratios and population-attributable risk factors for ischemic stroke by multivariable regression models

\begin{tabular}{|c|c|c|c|c|c|}
\hline Variables & Reference groups & Control groups & Odds ratio $(95 \% \mathrm{Cl})$ & $P$ value & PAR (\%) $(95 \%$ Cl) \\
\hline Sex & Female & Male & $1.13(1.02-1.56)$ & 0.013 & NA \\
\hline \multirow[t]{4}{*}{ Age, y } & \multirow[t]{4}{*}{$40-49$} & $50-59$ & $1.67(1.22-2.13)$ & \multirow[t]{4}{*}{$<0.001$} & NA \\
\hline & & $60-69$ & $3.12(1.92-3.25)$ & & NA \\
\hline & & $70-79$ & $4.36(2.44-5.38)$ & & NA \\
\hline & & $\geq 80$ & $5.54(2.38-6.49)$ & & NA \\
\hline Residence & Rural & Urban & $0.96(0.87-0.97)$ & 0.512 & NA \\
\hline \multirow[t]{3}{*}{ Education } & \multirow[t]{3}{*}{ Primary school or below } & Junior middle school & $0.94(0.82-1.43)$ & \multirow[t]{3}{*}{0.262} & NA \\
\hline & & Senior middle school & $0.92(0.84-1.25)$ & & NA \\
\hline & & College or above & $0.90(0.86-1.04)$ & & NA \\
\hline Overweight/obesity & No & Yes & $1.34(1.08-1.72)$ & 0.035 & $6.8(5.62-8.45)$ \\
\hline Smoking & No & Yes & $1.18(1.34-1.64)$ & 0.267 & $3.1(0.97-3.31)$ \\
\hline Physical inactivity & No & Yes & $1.97(1.33-3.02)$ & 0.008 & $9.7(9.82-15.93)$ \\
\hline Hypertension & No & Yes & $3.45(1.77-7.56)$ & $<0.001$ & $20.2(16.5-24.4)$ \\
\hline Diabetes & No & Yes & $1.65(1.31-2.35)$ & 0.026 & $5.7(5.22-7.54)$ \\
\hline Dyslipidemia & No & Yes & $2.03(1.42-3.96)$ & $<0.001$ & $11.2(7.84-9.93)$ \\
\hline Atrial fibrillation & No & Yes & $1.28(0.97-2.25)$ & 0.089 & $2.4(1.01-5.62)$ \\
\hline Family history & No & Yes & $1.94(1.26-3.02)$ & 0.011 & $7.9(8.32-13.64)$ \\
\hline
\end{tabular}

Cl confidence interval, PAR population-attributable risk, NA not applicable

among rural residents than urban residents, and personal daily consumption of vegetables and fruit is lower in rural areas than urban areas $[9,11]$. These may explain the differing stroke prevalence between urban and rural areas in China. However, in contrast with previous studies $[1,9,11]$, there was no significant difference in stroke prevalence between urban and rural areas in this survey. This indicated that disparities in residence was consistent with rapid economic development, and economic gap is narrowing between urban and rural areas.

In this survey, we found that hypertension, dyslipidemia and physical inactivity were strongest risk factors

Table 4 Odds ratios and population-attributable risk factors for hemorrhagic stroke by multivariable regression models

\begin{tabular}{|c|c|c|c|c|c|}
\hline Variables & Reference groups & Control groups & Odds ratio $(95 \% \mathrm{Cl})$ & $P$ value & PAR (\%) $(95 \%$ Cl) \\
\hline Sex & Female & Male & $0.91(0.86-1.46)$ & 0.364 & NA \\
\hline \multirow[t]{4}{*}{ Age, y } & \multirow[t]{4}{*}{$40-49$} & $50-59$ & $1.62(0.75-2.64)$ & \multirow[t]{4}{*}{0.143} & NA \\
\hline & & $60-69$ & $2.13(1.02-4.68)$ & & NA \\
\hline & & 70-79 & $1.96(0.92-3.12)$ & & NA \\
\hline & & $\geq 80$ & $1.73(0.96-2.97)$ & & NA \\
\hline Residence & Rural & Urban & $0.98(0.68-1.35)$ & 0.462 & NA \\
\hline \multirow[t]{3}{*}{ Education } & \multirow[t]{3}{*}{ Primary school or below } & Junior middle school & $1.12(0.76-2.25)$ & \multirow[t]{3}{*}{0.275} & NA \\
\hline & & Senior middle school & $0.93(0.85-1.58)$ & & NA \\
\hline & & College or above & $0.92(0.77-1.62)$ & & NA \\
\hline Overweight/obesity & No & Yes & $1.11(0.67-1.65)$ & 0.215 & $2.6(0.99-3.84)$ \\
\hline Smoking & No & Yes & $1.23(0.96-1.96)$ & 0.464 & $1.5(0.89-1.93)$ \\
\hline Physical inactivity & No & Yes & $1.09(0.89-2.15)$ & 0.233 & $1.9(0.93-2.65)$ \\
\hline Hypertension & No & Yes & $3.66(1.82-8.23)$ & $<0.001$ & $15.3(13.2-17.5)$ \\
\hline Diabetes & No & Yes & $1.26(0.96-2.56)$ & 0.435 & $2.5(0.96-3.45)$ \\
\hline Dyslipidemia & No & Yes & $1.28(0.86-1.87)$ & 0.289 & $2.3(0.97-2.81)$ \\
\hline Atrial fibrillation & No & Yes & $1.29(0.91-1.59)$ & 0.364 & $2.1(0.98-2.62)$ \\
\hline Family history & No & Yes & $1.63(0.99-3.04)$ & 0.086 & $5.8(1.02-8.32)$ \\
\hline
\end{tabular}

Cl confidence interval, PAR population-attributable risk, NA not applicable 
for overall stroke, with PAR of 23.6, 10.8 and 10.3\%, respectively, and followed by family history of stroke, diabetes, and overweight. Hypertension appeared to be the most important contributor for stroke, however, only $29.7 \%(2082 / 7018)$ of patients with hypertension receiving antihypertensive treatment in this survey. Our finding was consistent with previous studies [27, 28]. In China, the prevalence of hypertension substantially increased from 1979. However, the proportions of awareness, treatment, and control of hypertension decreased or remained constant in China from 2000 to 2010 [1, 9], whereas they have substantially increased in the highincome countries [29], these may affect the prevalence of stroke. Our results showed that the prevalence of dyslipidemia and the proportions of physical inactivity were higher than the national levels in recent studies [1, 30, 31]. The prevalence of hyperlipidemia increased from $8 \%$ in 1985 to $11.2 \%$ in 2014 in China [1, 32]. Population in physical activity decreased by 25\% from 1991 to 2011 [33], and increased energy intake of fat may increase in obesity and dyslipidemia in the Chinese population [34], consequently increasing the risk of overweight or obese and the related metabolic abnormalities. The high prevalence of hypertension and dyslipidemia might be ascribed to dietary preferences and low physical activity in residents of Sichuan Province. In contrast to previous studies $[27,28]$, smoking only accounted for $5.2 \%$ of the PAR for stroke in this study, this may be due to the significant decrease in the prevalence of smoking from $30.4 \%$ in 1980 to $24.2 \%$ in 2012 [35]. In addition, according to other studies, the prevalence of smoking was higher in male than in female $[1,36]$. In Sichuan, many male residents leave their home town to external work, this may be one of reasons of low the proportions of men and low the prevalence of smoking in this survey. Based on our aforementioned findings, clinical control of hypertension and hyperlipidemia, and behavioral interventions for metabolic and lifestyle risk factors are very important for preventing stroke.

Compared with previous Chinese studies [4], prevalence of hemorrhagic stroke was comparatively lower, and only hypertension was significantly associated with hemorrhagic stroke in this survey. The reasons for this difference may due to differences in study design, and the high case-fatality of hemorrhagic stroke could partially explain our observation of fewer hemorrhagic stroke patients in survivors [14]. However, because the DALYs for hemorrhagic stroke were very higher than those for ischemic stroke in China, the burden of hemorrhagic stroke remains, despite its low prevalence $[7,27,36]$. This finding also indicates that antihypertensive therapy is very important to decrease prevalence of hemorrhagic stroke.

Although this was the most recent investigation of stroke, high risk population for stroke, and associated risk factors in Sichuan, this cross sectional survey involved a large representative sample of the Sichuan. Several limitations of this study should be noted. First, this study was the cross sectional study, and there may have the recall bias because of the self-reported questionnaire. Second, we only screened residents for ages $\geq 40$ years; therefore, our present results cannot be generalized to all population groups in Southwestern China. Third, as known to all, atrial fibrillation is an important risk factor for stroke, it increases stroke risk by 5 times [37]. The prevalence of atrial fibrillation was very low in the survey, the respondents' atrial fibrillation status was based on self-report and ordinary ECG, which may have underestimated paroxysmal atrial fibrillation [38]. Finally, some other risk factors (such as alcohol intake, air pollutants and dietary patterns,) are shown to contribute to stroke risk [36], we were unable to involve them in present analyses due to lack of these information in this survey. Furthermore, our study did not prospective follow-up of participants and collect information about mortality or cause of death, and assess intracranial arterial disease in participants. In future studies, we plan to prospective follow-up participants, collect information about mortality or cause of death, and investigate stroke incidence in participants.

\section{Conclusion}

In this study, we have identified a high prevalence of stroke and high risk population for stroke, and related risk factors of stroke among adults aged $\geq 40$ years in southwestern China. Hypertension, dyslipidemia and lack of exercise were stronger contributors for overall stroke, followed by family history of stroke, diabetes, and overweight, and these factors are appropriate targets for the primary prevention of stroke. Individual-level and population-level interventions to control these leading risk factors of stroke identified in present study are needed to reduce the burden of stroke in southwestern China.

\section{Abbreviations \\ AF: atrial fibrillation; BMI: body mass index; Cl: confidence interval; CNSSS: china national stroke screening survey; DALYs: disability-adjusted life years; ECG: electrocardiogram; FBG: fasting blood glucose; LDL-C: low-density lipoprotein cholesterol; MIR: mortality-to-incidence ratio; OR: odds ratio; PARs: population-attributable risks; TC: cholesterol; TG: triglycerides}

\section{Acknowledgments}

None.

\section{Authors' contributions}

$X Y$ participated in the design of the study and drafted the manuscript. HL participated in the design of the study and statistical analysis. MY

participated in the design of the study and drafted the Tables. JZ carried out carotid ultrasonography and helped to draft the manuscript. XC participated in population survey and drafted the Fig. LT and WW participated in population survey. $J \mathrm{~L}$ helped to draft the manuscript and statistical analysis. All authors read and approved the final manuscript. 


\section{Funding}

This study was supported in part by grants from the Scientific Research Foundation of Sichuan Provincial Health Department (Grant No. 16ZD046) and the Sichuan Science and Technology Agency Research Foundation (Grant No.2018JY0164). The funding body did not participate in the design of the study; collection, analysis, and interpretation of data; and in writing the manuscript.

\section{Availability of data and materials}

The datasets used and/or analysed during the current study are available from the corresponding author on reasonable request.

\section{Ethics approval and consent to participate}

The study protocol was submitted to and approved by the Ethics Committee of the People's Hospital of Deyang City, the Affiliated Hospital of Southwest Medical University, and Suining Central Hospital. All procedures performed in studies involving human participants were in accordance with the ethical standards of the institutional and national research committee and with the 1964 Helsinki declaration and its later amendments or comparable ethical standards. Written informed consent was obtained from all individual participants included in the study.

\section{Consent for publication}

Not applicable.

\section{Competing interests}

The authors declare that they have no competing interests.

\section{Author details}

'Department of Neurology, The People's Hospital of Deyang City, No 173, North Taishan Road, Deyang 618000, Sichuan, China. ${ }^{2}$ Department of Neurology, The Affiliated Hospital of Southwest Medical University, Luzhou 646000 , Sichuan, China. ${ }^{3}$ Department of Neurology, the Suining Central Hospital, Suining 629000, Sichuan, China. ${ }^{4}$ Centre of rehabilitation, the People's Hospital of Deyang City, Deyang 618000, Sichuan, China.

\section{Received: 1 November 2019 Accepted: 29 December 2019} Published online: 07 January 2020

\section{References}

1. Guan T, Ma J, Li M, Xue T, Lan Z, Guo J, et al. Rapid transitions in the epidemiology of stroke and its risk factors in China from 2002 to 2013. Neurology. 2017:89:53-61.

2. Jiang B, Wang WZ, Chen H, Hong Z, Yang QD, Wu SP, et al. Incidence and trends of stroke and its subtypes in China: results from three large cities. Stroke. 2006;37:63-8

3. Liu L, Wang D, Wong KS, Wang Y. Stroke and stroke care in China: huge burden, significant workload, and a national priority. Stroke. 2011;42:3651-4.

4. Liu M, Wu B, Wang WZ, Lee LM, Zhang SH, Kong LZ. Stroke in China: epidemiology, prevention, and management strategies. Lancet Neurol. 2007; 6:456-64.

5. Wang Y, Cui L, Ji X, Dong Q, Zeng J, Wang Y, et al. The China National Stroke Registry for patients with acute cerebrovascular events: design, rationale, and baseline patient characteristics. Int J Stroke. 2011;6:355-61.

6. Longde $W$, Ling $Y$, Yang H, Yi Z, Yongjun W, Xunming J, et al. Fixed-dose combination treatment after stroke for secondary prevention in China: a national community-based study. Stroke. 2015;46:1295-300.

7. Feigin VL, Forouzanfar MH, Krishnamurthi R, Mensah GA, Connor M, Bennett DA, et al. Global and regional burden of stroke during 1990-2010: findings from the global burden of disease study 2010. Lancet. 2014;383:245-54.

8. GBD 2016 Lifetime Risk of Stroke Collaborators, Feigin VL, Nguyen G, Cercy K, Johnson CO, Alam T, Parmar PG, et al. Global, Regional, and CountrySpecific Lifetime Risks of Stroke, 1990 and 2016. N Engl J Med. 2018;379: 2429-37.

9. Wu S, Wu B, Liu M, Chen Z, Wang W, Anderson CS, et al. Stroke in China: advances and challenges in epidemiology, prevention, and management. Lancet Neurol. 2019;18:394-405.

10. Wang W, Jiang B, Sun H, Ru X, Sun D, Wang L, et al. Prevalence, incidence, and mortality of stroke in China: results from a nationwide populationbased survey of 480687 adults. Circulation. 2017;135:759-71.
11. Ru X, Wang W, Sun H, Sun D, Fu J, Ge S, et al. Geographical difference, rural-urban transition and trend in stroke prevalence in China: findings from a National Epidemiological Survey of stroke in China. Sci Rep. 2019;9(1): 17330. https://doi.org/10.1038/s41598-019-53848-1.

12. GBD 2016 Healthcare Access and Quality Collaborators. Measuring performance on the Healthcare Access and Quality Index for 195 countries and territories and selected subnational locations: a systematic analysis from the Global Burden of Disease Study 2016. Lancet. 2018;391:2236-71.

13. National Center for Stroke Control and Prevention, National Health and Family Planning Commission of the People's Republic of China. The China National Stroke Screening Survey Guidelines [online, in Chinese]. Available at: cnstroke. com/WebManage/InterveneProject/Index. Accessed 18 Nov 2016.

14. Krishnamurthi RV, Moran AE, Feigin VL, Barker-Collo S, Norrving B, Mensah GA, et al. Stroke prevalence, mortality and disability-adjusted life years in adults aged 20-64 years in 1990-2013: data from the global burden of disease 2013 study. Neuroepidemiology. 2015;45:190-202.

15. Asplund K, Tuomilehto J, Stegmayr B, Wester PO, Tunstall-Pedoe H. Diagnostic criteria and quality control of the registration of stroke events in the MONICA project. Acta Med Scand Suppl. 1988;728:26-39.

16. James PA, Oparil S, Carter BL, Cushman WC, Dennison-Himmelfarb C, Handler J, et al. Evidence-based guideline for the management of high blood pressure in adults: report from the panel members appointed to the eighth joint National Committee (JNC 8). JAMA. 2014;311:507-20.

17. American Diabetes Association. Diagnosis and classification of diabetes mellitus. Diabetes Care. 2013;36:S67-74.

18. Yi X, Han Z, Zhou Q, Lin J, Liu P. 20-Hydroxyeicosatetraenoic acid as a predictor of neurological deterioration in acute minor ischemic stroke. Stroke. 2016;47:3045-7.

19. Rao W, Su Y, Yang G, Ma Y, Liu R, Zhang S, et al. Cross-sectional associations between body mass index and hyperlipidemia among adults in northeastern China. Int J Environ Res Public Health. 2016; 13(5). doi: https:// doi.org/10.3390/ijerph13050516.

20. Zhang FL, Guo ZN, Wu YH, Liu HY, Luo Y, Sun MS, et al. Prevalence of stroke and associated risk factors: a population based cross sectional studyfrom northeast China. BMJ Open. 2017;7(9):e015758. https://doi.org/10.1136/ bmjopen-2016-015758.

21. Lyden PD, Lu M, Levine SR, Brott TG, Broderick J. A modified National Institutes of Health Stroke Scale for use in stroke clinical trials: preliminaryreliability and validity. Stroke. 2001;32:1310-7.

22. Stroke Screening and Prevention Project Committee NHaFPCoC. Technical specification of stroke screening and prevention in China. Chinese J Frontiers Med Sci. 2013;9:44-50.

23. Bruzzi P, Green SB, Byar DP, Brinton LA, Schairer C. Estimating the population attributable risk for multiple risk factors using case-control data. Am J Epidemiol. 1985;122:904-14.

24. Kooperberg C, Petitti DB. Using logistic regression to estimate the adjusted attributable risk of low birthweight in an unmatched case-control study. Epidemiology. 1991;2:363-6.

25. Li SC, Schoenberg BS, Wang CC, Cheng XM, Bolis CL, Wang KJ. Cerebrovascular disease in the People's Republic of China: epidemiologic and clinical features. Neurology. 1985;35:1708-13.

26. Cheng XM, Ziegler DK, Lai YH, Li SC, Jiang GX, Du XL, et al. Stroke in China, 1986 through 1990. Stroke. 1995:26:1990-4.

27. Zhou M, Wang H, Zeng X, Yin P, Zhu J, Chen W, et al. Mortality, morbidity, and risk factors in China and its provinces, 1990-2017: a systematic analysis for the Global Burden of Disease Study 2017. Lancet. 2019;394:1145-58.

28. O'Donnell MJ, Xavier D, Liu L, Zhang H, Chin SL, Rao-Melacini P, et al. Risk factors for ischaemic and intracerebral haemorrhagic stroke in 22 countries (the INTERSTROKE study): a case-control study. Lancet. 2010:376:112-23.

29. Mills KT, Bundy JD, Kelly TN, Reed JE, Kearney PM, Reynolds K, et al. Global disparities of hypertension prevalence and control clinical perspective. Circulation. 2016:134:441-50.

30. Pan L, Yang Z, Wu Y, Yin RX, Liao Y, Wang J, et al. The prevalence, awareness, treatment and control of dyslipidemia among adults in China. Atherosclerosis. 2016;248:2-9.

31. Wang $\mathrm{S}, \mathrm{Xu} \mathrm{L}$, Jonas JB, You QS, Wang YX, Yang $\mathrm{H}$. Prevalence and associated factors of dyslipidemia in the adult Chinese population. PLoS One. 2011;6:e17326.

32. Kesteloot H, Huang DX, Yang XS, Claes J, Rosseneu M, Geboers J, et al. Serum lipids in the People's republic of China: comparison of western and eastern populations. Arteriosclerosis. 1985;5:427-33. 
33. Ng SW, Howard AG, Wang HJ, Su C, Zhang B. The physical activity transition among adults in China: 1991-2011. Obes Rev. 2014;15:27-36.

34. Popkin BM. Synthesis and implications: China's nutrition transition in the context of changes across other low- and middle-income countries. Obes Rev. 2014;15:60-7.

35. Ng M, Freeman MK, Fleming TD, Robinson M, Dwyer-Lindgren L, Thomson B, et al. Smoking prevalence and cigarette consumption in 187 countries, 1980-2012. JAMA. 2014;311:183-92.

36. Feigin VL, Roth GA, Naghavi M, Parmar P, Krishnamurthi R, Chugh $\mathrm{S}$, et al. Global burden of diseases, injuries and risk factors study 2013 and stroke experts writing group; global burden of stroke and risk factors in 188 countries, during 1990-2013: a systematic analysis for the global burden of disease study 2013. Lancet Neurol. 2016;15:913-24.

37. Sposato LA, Cipriano LE, Saposnik G, Ruíz Vargas E, Riccio PM, Hachinski V. Diagnosis of atrial fibrillation after stroke and transient ischaemic attack: a systematic review and meta-analysis. Lancet Neurol. 2015;14:377-87.

38. Koga M, Yoshimura S, Hasegawa Y, Shibuya S, Ito Y, Matsuoka H, et al. SAMURAI study investigators. Higher risk of ischemic events in secondary prevention for patients with persistent than those with paroxysmal atrial fibrillation. Stroke. 2016;47:2582-8.

\section{Publisher's Note}

Springer Nature remains neutral with regard to jurisdictional claims in published maps and institutional affiliations.

Ready to submit your research? Choose BMC and benefit from:

- fast, convenient online submission

- thorough peer review by experienced researchers in your field

- rapid publication on acceptance

- support for research data, including large and complex data types

- gold Open Access which fosters wider collaboration and increased citations

- maximum visibility for your research: over $100 \mathrm{M}$ website views per year

At BMC, research is always in progress.

Learn more biomedcentral.com/submissions 